foundation of the Irish part of this journal was Arthur Jacob, one of the Masters of British Ophthalmology.

The centenary number contains a short history of the journal during its hundred years existence by Dr. Rowlette, of Dublin; the paper by Sir StClair Thomson on Victorian age, medical celebrities from the cartoons in Vanity Fair ; papers on the last hundred years of medicine, surgery and obstetrics, by. Dr. Cecil Wall, Mr. Walter Spencer and Mr. A. C. Palmer respectively, and a paper by Sir Ernest Graham-Little on the history of medical education during the last hundred years. There is also an account of Dr. James Yearsley, who had much to do with founding the Medical Circular, a short account of the first English medical journal of 1684, and a chronological list of Medical Societies and Journals in the British Isles.

Besides these graver matters there are some sprightly medical epigrams and entertaining snippets from the past. The number reflects the greatest credit on all concerned in its production and the Editor and his assistants are much to be congratulated on the present high standing of their paper.

\title{
CORRESPONDENCE
}

\section{"RETICULAR SUPERFICAL 'VACUOLATION' OF THE CORNEA."}

To the Editors of THE BRITISH JouRnal of Ophthalmology

DEAR SIRS, - In the issue of the Brit. Jl. of Ophthal. for March, 1937, p. 156, I gave a brief description of a certain condition under this title. I did not illustrate it. The delicacy of the condition renders it not easy to portray. As I have included a semi-diagramatic representation of the condition on p. 198 of my article in the present issue, may I be allowed to draw separate attention to the fact as the condition is an interesting one meriting study. The drawing here reproduced is an abstraction; it is not an actual copy of a case.

$$
\begin{aligned}
& \text { I am, Sir, } \\
& \text { Yours truly, } \\
& \text { BASIL GRAves. }
\end{aligned}
$$

LONDON.

Jannary 9, 1939. 